\title{
Distribution of polymorphisms in the CYP2C19 and $A B C B 1$ genes among patients with acute coronary syndrome in Lower Silesian population
}

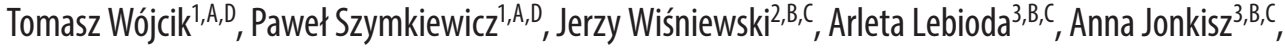 \\ Andrzej Gamian ${ }^{2, C, E}$, Wiktor Kuliczkowski ${ }^{1, A, E},{ }^{2}$ Krzysztof Ściborski ${ }^{1, D}$, Andrzej Mysiak ${ }^{1, A, E}$, Marcin Protasiewicz ${ }^{1, A, D-F}$ \\ ${ }^{1}$ Department and Clinic of Cardiology, Wroclaw Medical University, Poland \\ 2 Department and Section of Biochemistry, Wroclaw Medical University, Poland \\ ${ }^{3}$ Section of Molecular Techniques, Wroclaw Medical University, Poland \\ A - research concept and design; B - collection and/or assembly of data; C - data analysis and interpretation; \\ $D$ - writing the article; $E$ - critical revision of the article; $F$ - final approval of the article
}

Address for correspondence

Tomasz Wójcik

E-mail: t.k.woojcik@gmail.com

Funding sources

None declared

Conflict of interest

None declared

Received on December 11, 2018

Reviewed on March 27, 2019

Accepted on June 27, 2019

Published online on November 28, 2019

Cite as

Wójcik T, Szymkiewicz P, Wiśniewski J, et al. Distribution of polymorphisms in the CYP2C19 and $A B C B 1$ genes among patients with acute coronary syndrome in Lower Silesian population. Adv Clin Exp Med. 2019;28(12):1621-1626. doi:10.17219/acem/110322

DOI

10.17219/acem/110322

Copyright

Copyright by Author(s)

This is an article distributed under the terms of the

Creative Commons Attribution Non-Commercial License

(http://creativecommons.org/licenses/by-nc-nd/4.0/)

\begin{abstract}
Background. Dual antiplatelet therapy (DAPT) with aspirin and clopidogrel administered to treat patients with acute coronary syndrome (ACS) is still being used. However, despite the proven efficacy of this treatment regimen, thromboembolic complications have been observed in some individuals. The reason for this phenomenon is linked to the so-called increased responsiveness of platelets despite high platelet resistance (HPR). A significant role in HPR is attributed to genetically determined differences in the absorption and activation of clopidogrel.
\end{abstract}

Objectives. The aim of the study was to assess the incidence of polymorphisms of the $A B C B 1$ and CYPC19 genes that encode proteins involved in the absorption and metabolism of clopidogrel.

Material and methods. The analysis was performed in 199 consecutive patients from Lower Silesian voivodeship (Poland) who underwent coronary angioplasty with stenting for ACS. The single nucleotide polymorphism of the CYP2C19 and ABCB1 genes was performed using a mini sequencing or restriction fragment length polymorphism method.

Results. The results of this study revealed the high incidence of patients who may be unresponsive to antiplatelet treatment due to genetic causes. The CYPC19*2 allele in the form of homozygote or mutation heterozygote appeared in $26.1 \%$ of the study population. ABCB1 (C3435C > T) polymorphism was associated with $84 \%$ of patients. The total incidence of allelic disorders of low drug absorption and metabolism reached $14.6 \%$.

Conclusions. The data obtained should prompt clinicians to use more recent antiplatelet agents (ticagrelor or prasugrel) first, instead of clopidogrel.

Key words: ABCB1, clopidogrel, Lower Silesia, polymorphism, CYP2C9 


\section{Introduction}

Dual antiplatel therapy (DAPT) with aspirin and clopidogrel has until recently been the gold standard for the treatment of acute coronary syndrome (ACS) patients. Nevertheless, despite the proven efficacy of this treatment regimen, thromboembolic complications continue to be observed in some patients. ${ }^{1,2}$ The reason for this phenomenon is associated with a so-called sustained increase in platelets activity, in spite of DAPT. This phenomenon may be due to an impaired aspirin response, but it is mainly associated with an ineffective treatment with clopidogrel.

A number of factors contribute to increased platelet reactivity. The lack of expected effects of DAPT is most likely due to non-compliance to treatment recommendations. However, the complexity of genetically conditioned absorption and activation of clopidogrel is also important. The action of clopidogrel is conditioned by the efficacy of the pro-drug conversion into its active form. This process largely depends on intestinal absorption and complex hepatic metabolism. The first step of clopidogrel activation takes place in the gastrointestinal tract. The $A B C B 1$ gene expression product, P-GP (glycoprotein), plays a key role here. It is a membrane protein of the gastrointestinal tract, which acts to regulate xenobiotics concentrations in the human body, including clopidogrel. Spot mutations in the $A B C B 1$ gene type C3435C > T, resulting in the emergence of mutation homozygotes (TT) or mutation heterozygotes (CT) in place of proper homozygotes (CC), imply (TT) increased P-GP activity. This activity causes an excessive rejection of clopidogrel, hindering its attainment of adequate plasma concentrations. The polymorphism of this gene has a negative influence on the clinical effects of clopidogrel treatment and may cause high platelet resistance (HPR). An even greater association with individual differences in response to clopidogrel treatment is attributed to cytochrome P450. Its proper functioning allows for the final conversion of clopidogrel to its active metabolite.

Genetic studies are particularly difficult due to the numerous polymorphisms in the genes encoding CYP. CYP2C19, CYP3A4/5 and CYP1A2 are the most well-studied genetic variants. CYP2C19 alleles of type $* 2-\% 8$ are these that impair the metabolism of clopidogrel. It was observed that having even 1 allele of CYP2C19*2 was associated with worse prognosis in a long-term follow-up of myocardial infarction with respect to the incidence of subsequent myocardial infarction, stroke and death. There have also been more cases of stent thrombosis in these patients. ${ }^{3,4}$ The effect of the allele *17 in laboratory conditions is expressed by lower values for maximum platelet aggregation, better platelet inhibition and higher plasma concentrations of the active metabolite. ${ }^{5}$ The clinical effect of increased transcriptional activity of this polymorphism was associated with more bleeding. There have been no significant benefits noticed in terms of ischemic events and stent thrombosis. ${ }^{6}$

In our research work, we evaluated the prevalence of polymorphism of major absorption genes $(A B C B 1)$ and clopidogrel metabolism (CYPC19*2, *3, "17) in patients treated with coronary angioplasty with stent implantation due to ACS.

\section{Material and method}

A total of 199 patients (133 males and 63 females), mean age $65.2 \pm 11.9$ years, randomized to the prospective study, were hospitalized for acute myocardial infarction, including unstable angina, with non ST-elevation myocardial infarction (NSTEMI), and ST-elevation myocardial infarction (ST-elevation MI). All patients engaged in the research were treated according to European Society of Cardiology (ESC) recommendations using coronary angioplasty with stent implantation. The study was approved by the appropriate research ethics committee, and all patients included in the study gave written informed consent. The basic de-

Table 1. Demographics

\begin{tabular}{|c|c|}
\hline Study group & 199 \\
\hline $\begin{array}{l}\text { Sex, n (\%) } \\
\text { male } \\
\text { female }\end{array}$ & $\begin{array}{c}133(66.8) \\
66(33.2)\end{array}$ \\
\hline Age [years] & $65.2 \pm 11.9$ \\
\hline Caucasian race, n (\%) & $199(100)$ \\
\hline Residents of Lower Silesia, n (\%) & $183(91.9)$ \\
\hline STE-ACS, n (\%) & $110(55.3)$ \\
\hline NSTE-ACS/UA, n (\%) & $89(44.7)$ \\
\hline BMI $\left[\mathrm{kg} / \mathrm{m}^{2}\right]$ & $27.7 \pm 4.0$ \\
\hline Diabetes, n (\%) & $40(20.1)$ \\
\hline $\begin{array}{l}\text { Hypertension, } n(\%) \\
1^{\text {st }} \text { grade } \\
2^{\text {nd }} \text { grade } \\
3^{\text {rd }} \text { grade }\end{array}$ & $\begin{array}{l}33(16.6) \\
68(34.1) \\
37(18.6)\end{array}$ \\
\hline Serum creatinine concentration [mg/dL] & $1.09 \pm 0.26$ \\
\hline $\mathrm{eGFR}\left[\mathrm{mL} / \mathrm{min} / \mathrm{m}^{2}\right]$ & $70.69 \pm 18.81$ \\
\hline Serum cholesterol [mg/dL] & $203.74 \pm 48.76$ \\
\hline LDL serum [mg/dL] & $128.52 \pm 41.08$ \\
\hline Smokers, n (\%) & 69 (34.6) \\
\hline $\operatorname{PLT}[1,000 / \mu \mathrm{L}]$ & $238.68 \pm 56.62$ \\
\hline MPV [fL] & $11.52 \pm 1.40$ \\
\hline $\mathrm{Hb}[\mathrm{g} / \mathrm{dL}]$ & $14.42 \pm 1.76$ \\
\hline
\end{tabular}

STE-ACS - ST-elevation acute coronary syndrome; NSTE-ACS - non ST-elevation acute coronary syndrome; UA - unstable angina; BMI - body mass index; eGFR - estimated glomerular filtration; LDL - lowdensity lipoprotein; PLT - platelet count; MPV - mean platelet volume; $\mathrm{Hb}$ - hemoglobin level.

mographic data of patients are presented in Table 1.

\section{Genetic research}

In order to identify genetic polymorphism identification, genetic material was extracted from $200 \mu \mathrm{L}$ of whole blood 
samples of each patient using the High Pure PCR Template Preparation Kit (Roche Diagnostics, Warszawa, Poland). Using the ability of the DNA to bind under certain conditions with silica, centrifugation of the lysate was carried out in a mini column containing the silica membrane, which was then rinsed twice with washing buffer. Finally, the membrane was given a mini column elution buffer to recover the purified DNA. Amplified polymerase chain reaction (PCR) was the next step with the use of 4 pairs of specific primers, respectively for: CYP2C19*17 (-3402C> T), CYP2C19*3, ABCB1 (C3435C> T) and CYP2C19*2, as well as Multiplex PCR Kit (Qiagen, Hilden, Germany), according to the manufacturer's instructions. Single-nucleotide (DNA) polymorphism of the CYP2C19*2, *3 and $A B C B 1$ genes was performed using a mini-sequencing technique, a PCR modification. The SNaPshot Multiplex Kit (Applied Biosystems - Thermo Fisher Scientific, Gdańsk, Poland) was used for the analysis according to the manufacturer's instructions. Purification of the duplicated genetic material was carried out with alkaline phosphatase digestion and exonuclease to eliminate primers and deoxynucleotides that were not consumed in PCR. The mini-sequencing reaction was performed with specific primers designed to hybridize to the template, ending before the designated polymorphic site. Dideoxynucleotide triphosphates (ddNTP), or fluorescent labeled terminators, were involved in the reaction. Product detection was performed with capillary electrophoresis on a 3130 Genetic Analyzer (Applied Biosystems - Thermo Fisher Scientific). The results were analyzed with the use of the GeneMapper ID v. 3.2 program (Applied Biosystems, Foster City, USA) against the internal GeneScan ${ }^{\mathrm{TM}}$ LIZ 120 standard. To assess the polymorphism of CYP2C17*17 (locus $-3402 \mathrm{C}>\mathrm{T}$ ), a restriction fragment length polymorphism (RFLP) technique was used.

\section{Division into absorption and metabolic phenotypes}

The study population was divided into the group of "good absorbers" (GA), which included the wild-type homozygote $(\mathrm{CC})$, which lacked the $\mathrm{C} 3435 \mathrm{C}>\mathrm{T}$ spot mutation in the $A B C B 1$ gene, and the "poor absorbers" group (PA), which included the mutation heterozygotes (CT) and mutation homozygotes (TT) of the $A B C B 1$ gene.

Alleles that negatively affect clopidogrel metabolism (CYP2C *2, *3), and thus contribute to higher platelet reactivity in laboratory tests, have been assigned to the socalled loss-of-function (LoF) group. In contrast, alleles promoting the effects of clopidogrel (CYP2C *17), thus decreasing platelet aggregation, were given GoF (gain-offunction) name. For the purposes of the present work, patients were eligible for 2 metabolic groups, due to the polymorphism and the onset of the LoF or GoF allele:

- poor metabolizers (PM) - *2 or *3 carriers/non-*17 carriers - individuals with at least 1 LoF allele and no GoF allele;
- not poor metabolizers (NPM) - without the presence of any LoF allele (i.e., " 2 and *3) and simultaneously having at least $1 \mathrm{GoF}$ allele (i.e., "17) or patients without LoF (i.e., "2 and "3) and GoF (i.e., "17) or carriers simultaneously with both opposing alleles (*2 or *3 and simultaneously *17).

Patients with both PA and PM (PA + PM) phenotype were also isolated from the study group. The rest of the patients were referred to as not PA + PM.

\section{Results}

The basic demographic data of the study population is presented in Table 1. The data is typical of the population with ischemic heart disease.

\section{Genetic research}

The incidence of $A B C B 1$ polymorphism in the study group is shown in Fig. 1. The largest percentage of subjects were heterozygous (57.9\%). The minority of the patients were identified as wild-type homozygotes (CC). The incidence of CYP2C19*2 gene polymorphism is shown in Fig. 2. Most of the variants studied were patients with alleles coding for normal protein activity, but $26.1 \%$ of them had at least 1 mutation. No CYP2C19*3 allele was observed in the study population to reduce the activity of clopidogrel metabolism. A relatively high percentage of heterozygotes and wild-type homozygotes in the CYP2C19*17 allele were found in the study group (Fig. 3).

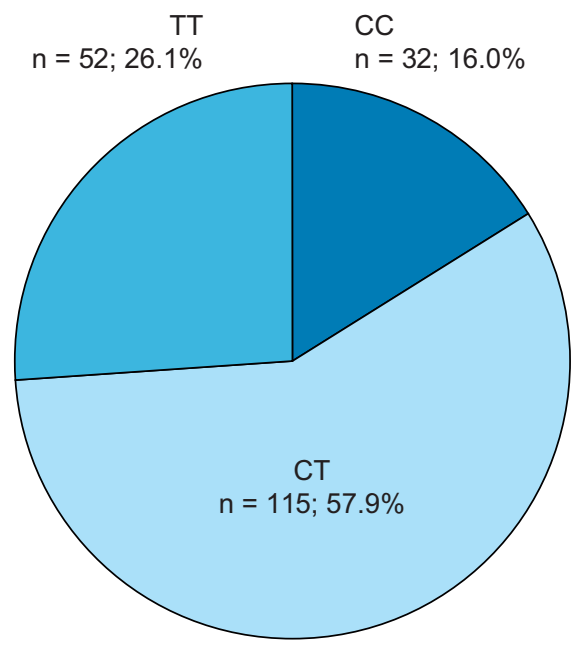

Fig. 1. Frequency of polymorphism of the $A B C B 1$ gene

CC - wild-type homozygote; CT - mutation heterozygote; TT - mutation homozygote.

\section{Division into absorption and metabolic phenotypes}

The incidence of clopidogrel GA and PA patients in the study population is shown in Fig. 4. The majority of the group were PA. Figure 5 shows the percentages 


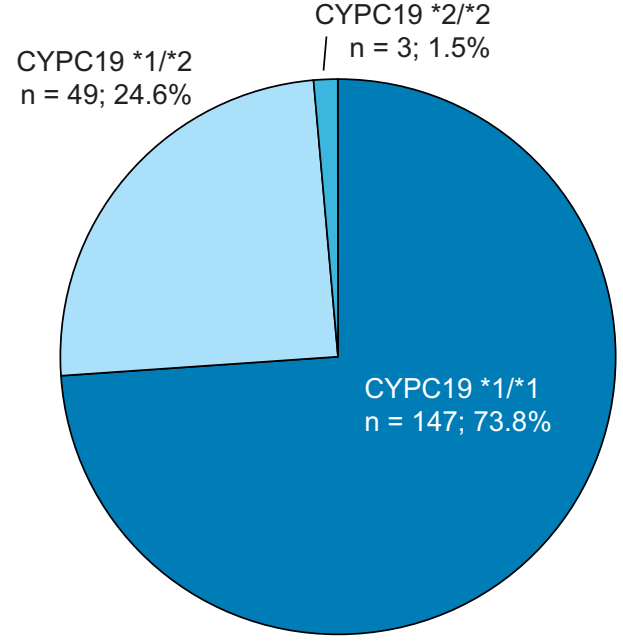

Fig. 2. Frequency of $\mathrm{CYPC} 19^{*} 2$ polymorphism

*1 - allele of normal CYP2C19 protein function; * 2 - CYP2C19 protein allelic dysfunction; ${ }^{*} 1 /{ }^{*} 1$ - wild-type homozygote; ${ }^{*} 1 / 2$ - mutation heterozygote; ${ }^{*} 2$ - mutation homozygote.

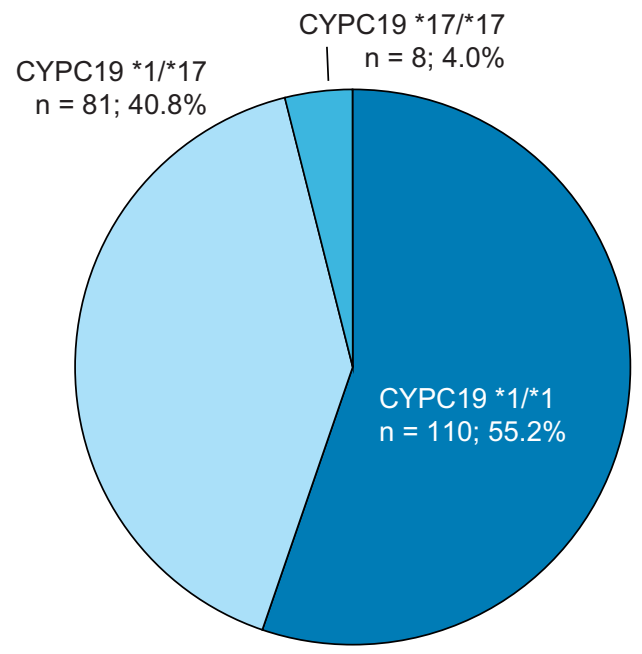

Fig. 3. Frequency of CYPC19*17 polymorphism

${ }^{*} 1$ - allele of the normal function of the CYP2C19 protein, *17 - allele improving the function of the CYP2C19 protein, ${ }^{* 1} /{ }^{*} 1$ - wild-type homozygote, ${ }^{*} 17$ - mutation heterozygote.

of individual metabolic phenotype in the study population. The relatively high proportion of patients (18\%) was found to be PM patients. The simutaneous incidence of PA and PM phenotypes is shown in Fig. 6. As many as 29 patients in the study group were members of this group.

\section{Discussion}

In this work, genetic testing was performed in a homogeneous ethnic group of patients with ACS. An important element of the study was the high homogeneity of the study group. Each of the 199 categorized patients was Caucasian, and $92 \%$ of the study group were residents of Lower Silesia.

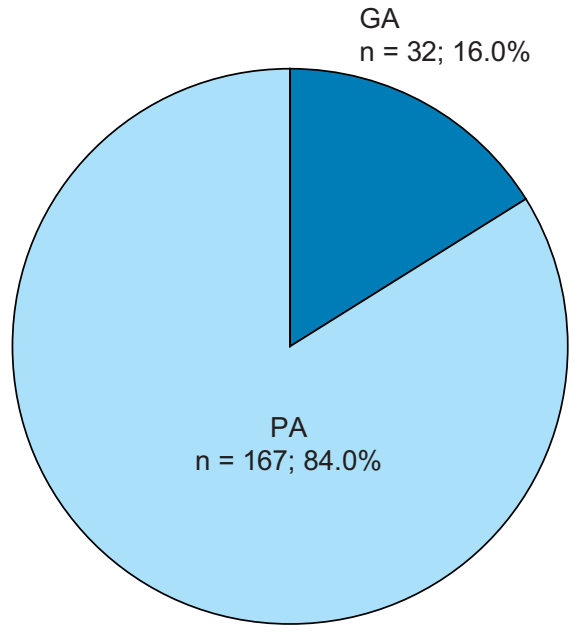

Fig. 4. Division into absorption phenotypes

PA - reduced absorption of clopidogrel; GA - good absorption of clopidogrel.

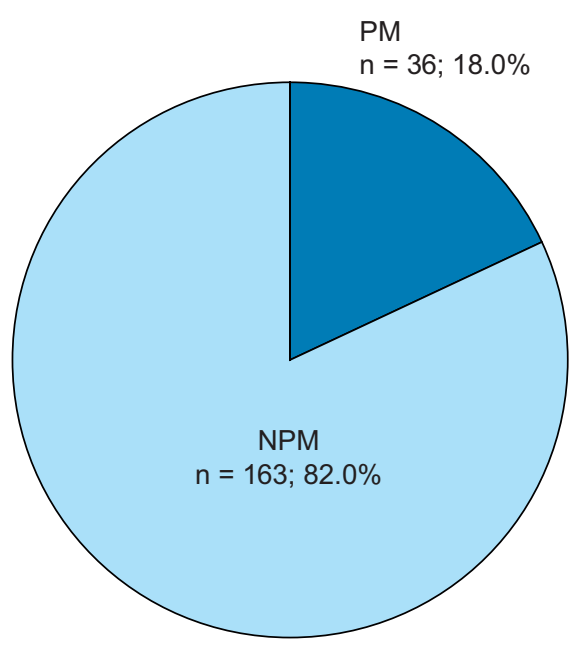

Fig. 5. Division into metabolic phenotypes

PM - poor metabolizers; NPM - not poor metabolizers.

$\mathrm{PA}+\mathrm{PM}$

$\mathrm{n}=29 ; 14.6 \%$

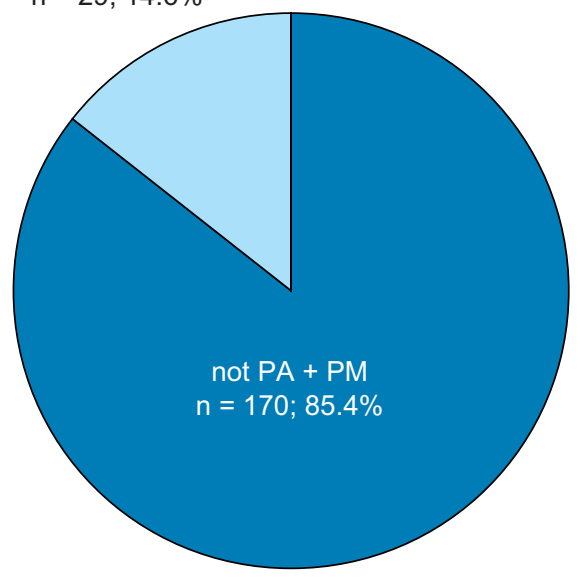

Fig. 6. Incidence of poor phenotype absorption and poor metabolism PA + PM - reduced absorption plus poor metabolism. 
The occurrence of $A B C B 1$ homozygous mutation polymorphism was demonstrated in $26.1 \%$ of the subjects $(\mathrm{n}=52)$, which is comparable to the $27 \%$ of the carriers of the modified gene present within the large TRITON-TIMI 38 study, based on a population of nearly 3,000 patients. ${ }^{7}$ Analyses concerning the variability of polymorphisms in various ethnic groups have revealed the prevalence of mutation homozygotes in the indigenous population of South America (27\%), among Caucasians (20\%) and Africans (13\%). ${ }^{8}$ The distribution of polymorphisms in $A B C B 1$ genes in the present study (CC $16.0 \%$, CT $57.9 \%$, TT $26.1 \%$ ) is almost identical to that observed in large, randomized, multicenter studies. The obtained data correlates well with the analysis of genotypes of healthy volunteers in West Pomerania ${ }^{9}$ and are slightly different with regards to wild-type homozygotes and heterozygotes among ACS patients in the population of Warszawa (CC 28\%, CT 51\%, TT 21\%). However, the homozygous mutations percentage is very alike in different groups, as demonstrated in the study by Śpiewak et al. ${ }^{10}$

The incidence of particular polymorphisms of the CYP2C19 variant depends on the ethnic group under consideration. The differences apply to each of the alleles being analyzed.

One of the dysfunctional alleles, CYP2C19*2, has been found in the East Asian population in the amount of up to $55 \%$. Among Africans, this polymorphism was observed in $40 \%$ of the subjects, and in the Caucasian population in Europe, the prevalence of CYP2C19*2 was reported in $30 \%$ of the subjects. ${ }^{11}$ In France, Collet et al. analyzed 259 patients with ACS episode. In their work, the wild-type homozygotes group of CYP2C19*1/*1 variant embraced $72 \%$ of the subjects, heterozygote $* 1 / * 225 \%$, and mutation homozygote ${ }^{*} 2 / * 2$ - only $2 \%{ }^{4}$ Almost identical results were obtained in German and Portuguese populations, and only slightly different results - in Hungarian population. ${ }^{12-14}$ As far as we know, the research on the prevalence of this polymorphism in the Polish population was conducted only once in a study by Malek et al. ${ }^{15}$ The authors reported that wild-type homozygotes appear in $80 \%$ of the population, heterozygotes in $18 \%$ and mutation homozygotes in $2 \%$. Our study has shown $73.9 \%$ of wild-type homozygotes, $24,6 \%$ of heterozygotes and $1,5 \%$ of mutation homozygotes; therefore, the data confirms the predecessors' observations.

The CYP2C19*3 allele frequencies tend to vary across human populations. Most often this polymorphism is observed in East Asia. The incidence of $* 1 / * 3$ genotype was reported by Jeong et al. at the level of $11 \% .{ }^{16}$ In Africa and Europe, this allele is much less frequent and sporadically exceeds $1 \%$. In the Italian population, this percentage was reported at $1.6 \%{ }^{17}$ and in Russian population at $0.3 \%{ }^{18}$ In our group of 188 patients, there was no single CYP2C19*3 mutation. To the best of our knowledge, our study is the first work which investigates the incidence of the CYP2C19*3 allele in the Polish population. The results confirm poor inspection of the discussed allele in this part of Europe.
Recently, CYP2C19*17 allele has been the most frequently reported polymorphism. In Europe, the heterozygous form of CYP2C19*17 allelic variant can be found in $31.7 \%$ of the population on average and the mutation homozygous - in $4.2 \%$. Thus, the differences concern populations all over Europe. In Germany, the incidence of at least 1 allele *17 was reported at the frequency of $41 \%$, in France $20 \%$ and in Sweden $18 \% .^{5,6,11}$ In Poland, Kurzawski et al. analyzed the distribution of these polymorphisms in a group of 125 patients and found allele * 17 in $27.2 \%$ of patients. ${ }^{20}$ Widespread dissemination of the allele polymorphism in Africa is rarely reported in literature, but some reports indicate a frequency similar to that of the Caucasian population. ${ }^{21}$ The incidence of the allele *17 in the Japanese population is estimated at $1.3 \%{ }^{22}$ and Chinese at $4 \% .{ }^{5}$ In our study on CYP2C19*17 polymorphisms, a higher incidence of this allele $(40.8 \%$ heterozygous individuals and $4 \%$ homozygotes) was found, compared to the study by Kurzawski et al. ${ }^{9}$ Nevertheless, when results obtained in this study are compared with those from a large group of over 1,500 German patients, one will find them to be very similar. ${ }^{6}$ They also correspond to the results of studies conducted and published in Poland by Kubica et al. ${ }^{23}$

In the study, the prevalence of the phenotype absorption and metabolism was assessed for the first time in the Polish population. As many as $14.6 \%$ of patients showed a cumulative occurrence of the polymorphism of the investigated genes which condition the malabsorption of clopidogrel and its impaired metabolism. The use of clopidogrel in this group of patients may pose a particular risk of achieving an inadequate effect of the drug and, hence, the risk of thromboembolic complications with all clinical implications.

The reported variability in polymorphism frequency, with confirmation of increased platelet reactivity despite clopidogrel administration, is a serious clinical problem. The presence of these polymorphisms is an independent and contributing factor to HPR and thromboembolic complications following ACS. This data, confirming a relatively high level of penetration in the area of clopidogrel polymorphisms, should prompt Polish clinicians to recommend firstly the most recent antiplatelet drugs (ticagrelor or prasugrel), in spite of significantly higher costs of such pharmacotherapy for their patients.

\section{ORCID iDs}

Tomasz Wójcik (D) https://orcid.org/0000-0001-9987-4872 Paweł Szymkiewicz (D) https://orcid.org/0000-0002-8469-6871 Jerzy Wiśniewski (D) https://orcid.org/0000-0003-2831-7643 Arleta Lebioda (D) https://orcid.org/0000-0001-5802-2155 Anna Jonkisz (D) https://orcid.org/0000-0001-6916-4212 Andrzej Gamian (D) https://orcid.org/0000-0002-2206-6591 Wiktor Kuliczkowski (D) https://orcid.org/0000-0001-6284-0820 Krzysztof Ściborski (D) https://orcid.org/0000-0002-3922-2861 Andrzej Mysiak (D) https://orcid.org/0000-0002-4728-2565 Marcin Protasiewicz (D) https://orcid.org/0000-0003-0253-0585 


\section{References}

1. Schomig A, Neumann FJ, Kastrati A, et al. A randomized comparison of antiplatelet and anticoagulant therapy after the placement of coronary-artery stents. N Engl J Med. 1996;334(17):1084-1089.

2. Claeys MJ. Antiplatelet therapy for elective coronary stenting: A moving target. Semin Vasc Med. 2003;3(4):415-418.

3. Mega JL, Close SL, Wiviott SD, et al. Cytochrome $\mathrm{p}-450$ polymorphisms and response to clopidogrel. N Engl J Med. 2009;360(4): 354-362.

4. Collet JP, Hulot JS, Pena A, et al. Cytochrome P450 2C19 polymorphism in young patients treated with clopidogrel after myocardial infarction: A cohort study. Lancet. 2009;373(9660):309-317.

5. Sim SC, Risinger C, Dahl ML, et al. A common novel CYP2C19 gene variant causes ultrarapid drug metabolism relevant for the drug response to proton pump inhibitors and antidepressants. Clin Pharmacol Ther. 2006;79(1):103-113.

6. Sibbing D, Koch W, Gebhard D, et al. Cytochrome $2 \mathrm{C} 19 * 17$ allelic variant, platelet aggregation, bleeding events, and stent thrombosis in clopidogrel-treated patients with coronary stent placement. Circulation. 2010;121(4):512-518.

7. Murphy SA, Antman EM, Wiviott SD, et al; TRITON-TIMI 38 Investigators. Reduction in recurrent cardiovascular events with prasugrel compared with clopidogrel in patients with acute coronary syndromes from the TRITON-TIMI 38 trial. Eur Heart J. 2008;29(20): 2473-2479.

8. Santos PC, Soares RA, Santos DB, et al. CYP2C19 and $A B C B 1$ gene polymorphisms are differently distributed according to ethnicity in the Brazilian general population. BMC Med Genet. 2011;12:13.

9. Kurzawski M, Pawlik A, Czerny B, Domański L, Rózański J, Droździk M. Frequencies of the common promoter polymorphisms in cytokine genes in a Polish population. Int J Immunogenet. 2005;32(5):285-291.

10. Śpiewak M, Malek LA, Kostrzewa G, et al. Influence of C3435T multidrug resistance gene-1 (MDR-1) polymorphism on platelet reactivity and prognosis in patients with acute coronary syndromes. Kardiol Pol. 2009;67(8):827-834.

11. Desta Z, Zhao X, Shin JG, Flockhart DA. Clinical significance of the cytochrome P450 2C19 genetic polymorphism. Clin Pharmacokinet. 2002;41(12):913-958.
12. Sibbing D, Stegherr J, Latz W, et al. Cytochrome P450 2C19 loss-offunction polymorphism and stent thrombosis following percutaneous coronary intervention. Eur Heart J. 2009;30(8):916-922.

13. Teixeira R, Monteiro P, Marques G, et al. CYP2C19*2 and prognosis after an acute coronary syndrome: Insights from a Portuguese center. Rev Port Cardiol. 2012;31(4):265-273.

14. Rideg $\mathrm{O}$, Haber A, Botz $\mathrm{L}$, et al. Pilot study for the characterization of pharmacogenetically relevant CYP2D6, CYP2C19 and $A B C B 1$ gene polymorphisms in the Hungarian population. Cell Biochem Funct. 2011;29(7):562-568.

15. Malek LA, Przyluski J, Spiewak M, et al. Cytochrome P450 2C19 polymorphism, suboptimal reperfusion and all-cause mortality in patients with acute myocardial infarction. Cardiology. 2010;117(2):81-87.

16. Jeong YH, Tantry US, Kim IS, et al. Effect of CYP2C19*2 and *3 lossof-function alleles on platelet reactivity and adverse clinical events in East Asian acute myocardial infarction survivors treated with clopidogrel and aspirin. Circ Cardiovasc Interv. 2011;4(6):585-594.

17. Scordo MG, Caputi AP, D'Arrigo C, Fava G, Spina E.Allele and genotype frequencies of CYP2C9, CYP2C19 and CYP2D6 in an Italian population. Pharmacol Res. 2004;50(2):195-200.

18. Gaikovitch EA, Cascorbi I, Mrozikiewicz PM, et al. Polymorphisms of drug metabolizing enzymes CYP2C9, CYP2C19, CYP2D6, CYP1A1, NAT2 and of P-glycoprotein in a Russian population. Eur J Clin Pharmacol. 2003;59(4):303-312.

19. Frere C, Cuisset T, Gaborit B, Alessi MC, Hulot JS. The CYP2C19*17 allele is associated with better platelet response to clopidogrel in patients admitted for non-ST acute coronary syndrome. J Thromb Haemost. 2009;7(8):1409-1411.

20. Kurzawski M, Gawrońska-Szklarz B, Wrześniewska J, Siuda A, Starzyńska T, Droździk M. Effect of CYP2C19*17 gene variant on Helicobacter pylori eradication in peptic ulcer patients. Eur J Clin Pharmacol. 2006;62(10):877-880.

21. Janha RE, Sisay-Joof F, Hamid-Adiamoh M, et al. Effects of genetic variation at the CYP2C19/CYP2C9 locus on pharmacokinetics of chlorcycloguanil in adult Gambians. Pharmacogenomics. 2009;10(9):1423-1431.

22. Sugimoto $K$, Uno T, Yamazaki $H$, Tateishi T. Limited frequency of the CYP2C19*17 allele and its minor role in a Japanese population. $\mathrm{Br} J$ Clin Pharmacol. 2008;65(3):437-439.

23. Kubica A, Kozinski M, Grzesk G, Fabiszak T, Navarese EP, Goch A. Genetic determinants of platelet response to clopidogrel. J Thromb Thrombolysis. 2011;32(4):459-466. 